\title{
Reliability of foveal avascular zone measurements in eyes with retinal vein occlusion using optical coherence tomography angiography
}

Bruno Mauricio Rodrigues de Oliveira* (0), Luis Filipe Nakayama, Bruno Rebello de Godoy, Alexandre Gomes Bortoloti de Azevedo, Flavio Eduardo Hirai and Somaia Mitne

\begin{abstract}
Background: To evaluate the reliability of foveal avascular zone (FAZ) area measurements using optical coherence tomography angiography (OCTA) in eyes with retinal vein occlusion (RVO).

Methods: Twenty-five OCTA exams of patients with RVO were evaluated retrospectively. Three examiners performed manual measurements of the $F A Z$, and interrater and intrarater reliability were obtained.

Results: The intraclass correlation coefficient (ICC) for interrater reliability for individual measurements was 0.62 (moderate) with a 95\% confidence interval (Cl) of 0.40 to $0.79(\mathrm{p}<0.001)$. The ICC $(95 \% \mathrm{Cl})$ for intrarater reliability was 0.92 ( 0.82 to 0.96 ) for rater $A, 0.96$ (0.91 to 0.98$)$ for $B$, and 0.88 ( 0.76 to 0.94$)$ for $C(p<0.001)$. In all subanalyses including presence of edema and type of occlusion, interrater reliability was poor/moderate, and intrarater reliability was good/excellent.

Conclusion: The FAZ varies significantly among eyes with RVO, so measurements obtained using OCTA should be analyzed with caution due to the moderate level of reliability among different examiners.
\end{abstract}

Keywords: Retina, Foveal avascular zone, OCT, Retinal vein occlusion

\section{Background}

Retinal vein occlusion (RVO) is a common retinal vascular disease that may lead to significant visual morbidity. The vascular obstruction can occur either in the central retinal vein or in a branch of the retinal vein [1-3]. Systemic vascular diseases are the most important risk factor for RVO, especially in elderly patients. Hypercoagulable states and systemic inflammatory conditions are also risk factors that must be considered in young patients, in whom RVO is uncommon.

*Correspondence: brunomro@gmail.com

Retina and Vitreous Sector, Department of Ophthalmology, Universidade Federal de São Paulo - Escola Paulista de Medicina, Rua Botucatu, 821,

Vila Clementino, São Paulo, SP 04023-062, Brazil
Visual outcome depends on the severity of retinal ischemia and macular edema. Hence, evaluation of the retinal vasculature is important for determining the therapeutic strategy and prognosis [1-3].

Fluorescein angiography (FA) has traditionally been used to analyze retinal capillary non-perfusion and neovascularization. FA is an invasive procedure involving intravenous dye injection that provides two-dimensional images with dynamic visualization of blood flow. Therefore, patterns of leakage, pooling and staining can be observed and correlated with clinical presentation. However, FA is unable to analyze the different retinal vasculature layers separately $[4,5]$.

The optical coherence tomography angiography (OCTA) allows visualization of vascular maps of the

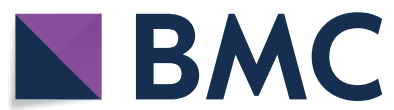

(c) The Author(s) 2020. This article is licensed under a Creative Commons Attribution 4.0 International License, which permits use, sharing, adaptation, distribution and reproduction in any medium or format, as long as you give appropriate credit to the original author(s) and the source, provide a link to the Creative Commons licence, and indicate if changes were made. The images or other third party material in this article are included in the article's Creative Commons licence, unless indicated otherwise in a credit line to the material. If material is not included in the article's Creative Commons licence and your intended use is not permitted by statutory regulation or exceeds the permitted use, you will need to obtain permission directly from the copyright holder. To view a copy of this licence, visit http://creativeco mmons.org/licenses/by/4.0/. The Creative Commons Public Domain Dedication waiver (http://creativecommons.org/publicdomain/ zero/1.0/) applies to the data made available in this article, unless otherwise stated in a credit line to the data. 
retina and choroid separated by layers and non-invasively $[6,7]$. OCTA can provide structural and functional information on the retina and choroidal vascularization and detect vascular flow at a fixed point in time [6]. In addition, due to the high resolution of the capillary information, OCTA permits measurement of the dimensions of the foveal avascular zone (FAZ). Previous studies have demonstrated the reliability of FAZ measurements by OCTA compared with the contralateral eye, albeit with great interobserver variability [8-10]. However, software platforms lack normalized data to determine whether microvascular changes are abnormal, and the reliability of FAZ measurements using OCTA in vascular retinal diseases is unclear $[11,12]$.

The aim of this study was to evaluate the reliability of FAZ area measurements in eyes with RVO obtained by swept-source OCTA using a Topcon DRI OCT Triton.

\section{Methods}

OCTA exams of consecutive patients attending retinal clinics at Federal University of São Paulo and diagnosed with RVO in the last 2 years were analyzed retrospectively. This study was approved by the UNIFESP Institutional Review Board and carried out in accordance with the tenets of the Declaration of Helsinki (Additional file 1).

The inclusion criteria were diagnosis of RVO (central or branch of the retinal vein) according to clinical evaluation and fundus retinal exam performed by at least two retina specialists. Patients were excluded from this study if their medical records documented a history of another ocular or clinical disease that may lead to retinal vascular abnormalities.

A Topcon DRI Triton swept-source optical coherence tomographer (Topcon Corporation, Japan) was used to obtain volumetric angiography maps of the retina. All exams met the quality thresholds given by the OCT software with a minimum index of 40 . A macular scan size of $6 \times 6 \mathrm{~mm}$ was used for FAZ evaluation at the superficial retinal vascular layer. Manual measurements were performed using the built-in IMAGEnet ${ }^{\circledR}$ software (Topcon Medical Systems, Inc.). Two retina specialists and one-third-year ophthalmology resident were recruited to perform the measurements of all patients blinded to each other's results.

Every examiner performed two measurements of each image at different times with an interval of at least 3 weeks between the two measurements. Before measurement, evaluation and correction of the segmentation of retinal layers for angiography analysis were performed at the discretion of the examiner. A previous study reported the importance of adjusting segmentation, including the full thickness of the retina, in order to reduce errors and variations [13].

Statistical analysis was performed with Stata v.14 (College Station, Texas, USA). To evaluate the interrater (between-observer) reliability of the measurements, we calculated the intraclass correlation coefficient (ICC) using a two-way random-effects model evaluating single raters for absolute agreement. For the intrarater (withinobserver) reliability test, we used a two-way mixed-effects model for absolute agreement between measurements within the rater.

The ICC takes a value from zero (no agreement) to one (complete agreement). For analysis purposes, we classified ICC values as follows: 0 to 0.50 , poor reliability; 0.50 to 75 , moderate reliability; 0.75 to 0.90 , good reliability; and greater than 0.90 , excellent reliability.

\section{Results}

Twenty-five patients were enrolled in this study, including 14 (56\%) males and 11 (44\%) females. The diagnosis was central RVO in 14 patients (56\%) and branch RVO in 11 patients (44\%). Eighteen patients (72\%) presented OCT scans with macular edema. The mean age of the patients was 56.7 (SD 12.5) years, with a range from 30 to 78 years (Table 1 ).

The individual FAZ measurements of the patients are shown in Table 2, along with the mean FAZ dimensions provided by each examiner (A, B and $\mathrm{C}$ ). To evaluate the consistency of the measurement process, statistical analysis was performed using the ICC to determine the repeatability (intrarater reliability) and reproducibility (interrater reliability).

The ICC for interrater reliability for individual measurements was 0.62 (moderate), with a 95\% confidence interval (CI) of 0.40 to $0.79(\mathrm{p}<0.001)$. When considering all raters as a group and analyzing the reliability between

\section{Table 1 Baseline characteristics of patients}

\begin{tabular}{lc}
\hline Characteristics & Sample (total =25) \\
\hline Gender & $14(56 \%)$ \\
Male & $11(44 \%)$ \\
Female & \\
Type of occlusion & $14(56 \%)$ \\
Central vein & $11(44 \%)$ \\
Branch vein & $56.7(12.5)$ \\
Mean age (SD) & $18(72 \%)$ \\
Presence of macular edema & $11(44 \%)$ \\
Affected eye & $14(56 \%)$ \\
Right eye & \\
Left eye &
\end{tabular}


Table 2 Foveal avascular zone (FAZ) measurements of each examiner

\begin{tabular}{|c|c|c|c|c|c|c|c|c|c|}
\hline & FAZ A1 & FAZ A2 & Mean A & FAZ B1 & FAZ B2 & Mean B & FAZC1 & FAZC2 & Mean C \\
\hline 1 & 529.453 & 519.609 & 524.531 & 986.836 & 1094.766 & 1040.801 & 862.646 & 835.313 & 848.9795 \\
\hline 2 & 312.539 & 361.758 & 337.1485 & 355.078 & 285.5 & 320.289 & 359.297 & 451.406 & 405.3515 \\
\hline 3 & 665.859 & 848.32 & 757.0895 & 351.563 & 375.117 & 363.34 & 316.758 & 412.734 & 364.746 \\
\hline 4 & 529.805 & 502.031 & 515.918 & 531.211 & 525.586 & 528.3985 & 567.07 & 576.211 & 571.6405 \\
\hline 5 & 880.312 & 582.188 & 731.25 & 504.492 & 547.031 & 525.7615 & 519.258 & 512.578 & 515.918 \\
\hline 6 & 545.625 & 926.367 & 735.996 & 411.328 & 525.234 & 468.281 & 672.891 & 1050.82 & 861.8555 \\
\hline 7 & 959.766 & 941.484 & 950.625 & 724.219 & 687.305 & 705.762 & 685.195 & 680.625 & 682.91 \\
\hline 8 & 392.695 & 273.516 & 333.1055 & 1174.219 & 1086.68 & 1130.4495 & 1406.602 & 1087.734 & 1247.168 \\
\hline 9 & 627.188 & 387.422 & 507.305 & 423.984 & 421.523 & 422.7535 & 413.086 & 387.07 & 400.078 \\
\hline 10 & 338.203 & 289.336 & 313.7695 & 443.32 & 368.789 & 406.0545 & 365.625 & 358.242 & 361.9335 \\
\hline 11 & 696.797 & 685.195 & 690.996 & 421.875 & 837.773 & 629.824 & 1147.5 & 770.273 & 958.8865 \\
\hline 12 & 413.086 & 533.32 & 473.203 & 354.375 & 348.398 & 351.3865 & 288.281 & 241.172 & 264.7265 \\
\hline 13 & 1506.797 & 1195.313 & 1351.055 & 773.438 & 1213.594 & 993.516 & 929.531 & 1499.063 & 1214.297 \\
\hline 14 & 1376.719 & 1406.953 & 1391.836 & 1429.102 & 1595.742 & 1512.422 & 1495.47 & 1514.18 & 1504.825 \\
\hline 15 & 206.719 & 265.43 & 236.0745 & 63.281 & 72.422 & 67.8515 & 80.156 & 85.43 & 82.793 \\
\hline 16 & 844.102 & 731.602 & 787.852 & 684.492 & 688.008 & 686.25 & 622.969 & 427.5 & 525.2345 \\
\hline 17 & 566.367 & 492.188 & 529.2775 & 601.172 & 759.375 & 680.2735 & 390.586 & 385.684 & 388.135 \\
\hline 18 & 1523.672 & 1567.07 & 1545.371 & 1978.945 & 2036.602 & 2007.7735 & 366.328 & 309.727 & 338.0275 \\
\hline 19 & 661.641 & 648.984 & 655.3125 & 224.648 & 208.125 & 216.3865 & 184.922 & 145.625 & 165.2735 \\
\hline 20 & 706.992 & 736.523 & 721.7575 & 355.586 & 364.57 & 360.078 & 342.773 & 248.203 & 295.488 \\
\hline 21 & 145.195 & 192.656 & 168.9255 & 76.641 & 74.883 & 75.762 & 218.32 & 235 & 226.66 \\
\hline 22 & 265.078 & 315 & 290.039 & 229.57 & 239.06 & 234.315 & 140.977 & 146.25 & 143.6135 \\
\hline 23 & 356.836 & 359.648 & 358.242 & 318.516 & 312.188 & 315.352 & 253.447 & 262.969 & 258.208 \\
\hline 24 & 368.086 & 458.086 & 413.086 & 485.156 & 464.063 & 474.6095 & 317.461 & 348.398 & 332.9295 \\
\hline 25 & 418.359 & 557.227 & 487.793 & 75.937 & 93.164 & 84.5505 & 396.211 & 354.375 & 375.293 \\
\hline
\end{tabular}

the average measurements, the ICC value was 0.83 (good), with a 95\% CI of 0.67 to 0.92 ( $\mathrm{p}<0.001$ ).

The ICC $(95 \% \mathrm{CI})$ for intrarater reliability was 0.92 (0.82 to 0.96 ) for rater A, 0.96 (0.91 to 0.98 ) for rater B, and 0.88 ( 0.76 to 0.94$)$ for rater $C$; these differences were significant $(\mathrm{p}<0.001)$.

Considering macular edema and type of occlusion (central or branch RVO), the ICC for interrater reliability for individual measurements was 0.75 (moderate) for central RVO (95\% CI $0.51-0.90$ and $\mathrm{p}<0.001$ ); 0.48 (poor) for branch RVO (95\% CI $0.12-0.80$ and $\mathrm{p}<0.05$ ); 0.62 (moderate) for macular edema $(95 \%$ CI $0.36-0.82$ and $\mathrm{p}<0.001$ ); and 0.58 (moderate) for the group without macular edema (95\% CI $0.11-0.90$ and $\mathrm{p}<0.05$ ).

For the above subanalyses, the intrarater reliabilities of raters $\mathrm{A}, \mathrm{B}$ and $\mathrm{C}$ were all good/excellent with statistical significance $(\mathrm{p}<0.001)$, as shown in Table 3 . There was no difference in reliability comparing different types of occlusion or presence of edema in the intrarater analysis.

\section{Discussion}

The FAZ is the macular capillary-free zone surrounded by interconnected capillary vessels. Its size correlates with the foveal circulation condition in retino-vascular diseases [1-3]. Previous studies have suggested a mean physiological FAZ area of 200 to $400 \mu \mathrm{m}^{2}$ in healthy subjects [8]. RVO leads to FAZ enlargement, and measurements of the FAZ therefore provide an objective evaluation of macular ischemia and consequently visual acuity prognosis [1].

Fluorescein angiography (FA) is the standard exam for FAZ evaluation, but the high variability in measurements diminishes the reliability of this method, even in healthy patients [8]. FA may also miss some microvasculature changes that are more readily observed in OCTA, including deep capillary plexus, which is mainly affected in RVO [1, 11]. Moreover, the FA exam cannot be performed in pregnant women and patients with fluorescein allergy, renal failure, severe asthma or significant cardiac disease [5].

OCTA is a dye-less method of imaging retinal circulation in different layers that allows a volumetric approach. 
Table 3 Intraclass correlation coefficient (ICC) for reliability analysis of foveal avascular zone (FAZ) measurements

\begin{tabular}{|c|c|c|c|}
\hline Rating & ICC & $95 \%$ & \\
\hline Interrater relia & & & \\
\hline Individual & 0.62 & 0.41 & 0.79 \\
\hline Average & 0.83 & 0.67 & 0.92 \\
\hline Intrarater relial & & & \\
\hline$A$ & 0.92 & 0.82 & 0.96 \\
\hline B & 0.96 & 0.91 & 0.98 \\
\hline C & 0.88 & 0.76 & 0.94 \\
\hline Interrater relia| & foccle & & \\
\hline Central vein & & & \\
\hline Individual & 0.75 & 0.51 & 0.90 \\
\hline Average & 0.90 & 0.76 & 0.96 \\
\hline Branch vein & & & \\
\hline Individual & 0.48 & 0.12 & 0.80 \\
\hline Average & 0.74 & 0.29 & 0.92 \\
\hline Interrater relia| & nce of & & \\
\hline Macular eder & & & \\
\hline Individual & 0.62 & 0.36 & 0.82 \\
\hline Average & 0.83 & 0.63 & 0.93 \\
\hline Without mac & & & \\
\hline Individual & 0.58 & 0.11 & 0.90 \\
\hline Average & 0.81 & 0.28 & 0.96 \\
\hline Intrarater reliak & foccly & & \\
\hline Central vein & & & \\
\hline A & 0.91 & 0.75 & 0.97 \\
\hline B & 0.99 & 0.96 & 0.99 \\
\hline C & 0.94 & 0.81 & 0.98 \\
\hline Branch vein $\mathrm{c}$ & & & \\
\hline A & 0.93 & 0.75 & 0.98 \\
\hline B & 0.94 & 0.80 & 0.98 \\
\hline C & 0.79 & 0.40 & 0.94 \\
\hline Intrarater reliak & nce of & & \\
\hline Macular eder & & & \\
\hline A & 0.91 & 0.78 & 0.97 \\
\hline B & 0.93 & 0.83 & 0.97 \\
\hline C & 0.87 & 0.69 & 0.95 \\
\hline Without mac & & & \\
\hline A & 0.91 & 0.57 & 0.98 \\
\hline B & 0.98 & 0.87 & 0.99 \\
\hline C & 0.90 & 0.53 & 0.98 \\
\hline
\end{tabular}

To avoid segmentation artifact manual correction of automatic retinal layers segmentation were performed in all OCT exams. En face retinal exam were evaluated to identify hemorrhages or opacities that could lead to shadowing and projection artifacts. In every OCTA exam artifacts must be considered and manual correction should be performed to decrease artifacts in exam and en face exam need to be analyzed altogether with OCTA vascular exam to reduce shadowing and projections artifacts.

Previous OCTA studies in healthy patients have suggested excellent reproducibility and repeatability in measurements of the FAZ [8], but few studies have considered macular pathologies such as macular ischemia or edema [14]. Although several studies have aimed to correlate OCTA findings such as enlargement of FAZ area, vascular network attenuation and retinal nonperfusion with the severity of retinal vascular diseases $[2$, 15-19], the reasons for the large variability in prognosis among patients and the role and impact of such anatomic features in clinical outcomes remain unclear [2]. Previous reports have identified qualitative and quantitative changes associated with RVO via OCTA. However, whether the quantitative data provided by OCTA software are accurate and can be correlated with macular function have not been established [11].

The present report indicated good/excellent intrarater reliability of manual FAZ measurements and satisfactory repeatability of FAZ area measurements via OCTA. By contrast, interrater reliability (i.e., reproducibility) was moderate, suggesting that FAZ measurements by different observers may not be comparable. Moreover, the great variability of FAZ dimensions (as shown in Table 2 and Fig. 1) make correlations with disease severity difficult. In addition, the present study did not demonstrate whether the type of occlusion and the presence of macular edema are factors that impact the reliability of FAZ measurements, even after review and correction of the segmentation of retinal layers for angiography analysis.

The main concern about OCTA image interpretation is the presence of artifacts, specially segmentation, projection, and masking artifacts. As mentioned above, segmentation artifacts can be reduced by using manual correction of retinal layers. Also, evaluation of en face retinal maps could avoid projection artifacts misinterpretation. However, a pronounced edema or highly reflective intraretinal structures could produce masking artifacts in underlying layers [20]. Previous reports noticed the absence of capillaries detection in the areas of retinal cysts [21, 22]. Couturier et al. hypothesized that retinal cysts provoke a displacement of the capillary in the cysts edges or more likely the cysts develop preferentially in nonperfusion areas [21]. Sellam et la reported that after cyst regression only $36 \%$ of the eyes improved vascular density in these areas [22].

The large number of artifacts in OCTA images segmentation and masking effects may complicate the proper judgement of FAZ limits, resulting in an irregular and inaccurate vascular map close to the fovea. 

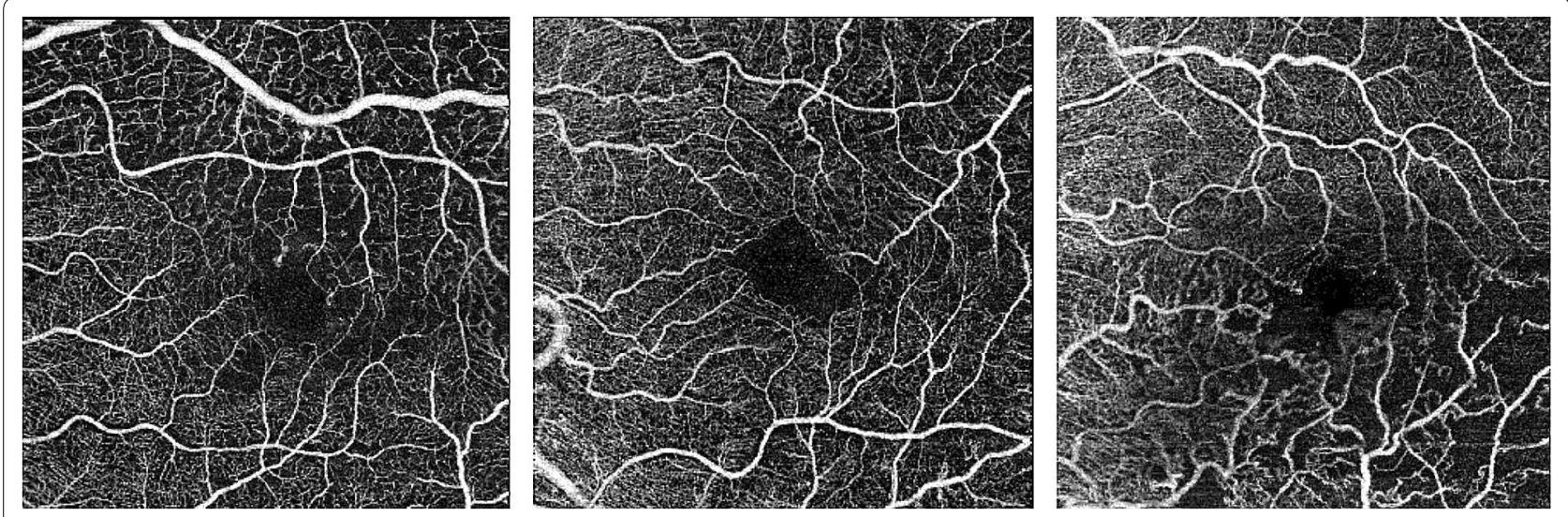

Fig. 1 OCTA maps of three different subjects with great variability of foveal avascular zone

Consequently, the results may not be interchangeable among patients. However, the good intrarater reliability observed in the present study suggests that the use of FAZ measurements for individual follow-up is feasible.

\section{Conclusion}

In summary, caution is advised when analyzing measurements of the FAZ area in eyes with RVO. Comparisons between examiners provide only moderate reliability, and the results may not be interchangeable.

\section{Supplementary information}

Supplementary information accompanies this paper at https://doi. org/10.1186/s40942-020-00237-w.

Additional file 1. Ethics Committee Approval provided by UNIFESP Institutional Review Board.

\section{Acknowledgements}

We would like to thank Ophthalmology sectors from Escola Paulista de Medicina/São Paulo Federal University.

\section{Authors' contributions}

BRG, AGBA and BMRO conceived and planned the manuscript. LFN and BMRO took the lead in writing and reviewing the manuscript. All authors contributed in an extensive exchange. SM coordinated the research. All authors read and approved the final manuscript.

\section{Funding}

No funding

\section{Availability of data and materials}

The datasets generated during the current study that were used to calculate the primary outcome parameters are available upon reasonable request from the corresponding author Oliveira, BMR.

\section{Ethics approval and consent ot participate}

Ethic Committee Number Unifesp: 0492/2019; CAAE: 12801919.3.0000.5505.

All participants signed informed consent.

\section{Consent for publication}

Not applicable.

\section{Competing interests}

The authors declare that they have no competing interests.

Received: 18 February 2020 Accepted: 22 July 2020

Published online: 03 August 2020

\section{References}

1. Adhi M, Filho MAB, Louzada RN, Kuehlewein L, de Carlo TE, Baumal CR, et al. Retinal capillary network and foveal avascular zone in eyes with vein occlusion and fellow eyes analyzed with optical coherence tomography angiography. Investig Opthalmol Vis Sci. 2016;57(9):OCT486

2. Kang J-W, Yoo R, Jo YH, Kim HC. Correlation of microvascular structures on optical coherence tomography angiography with visual acuity in retinal vein occlusion. Retina. 2017:37(9):1700-9.

3. Wons J, Pfau M, Wirth MA, Freiberg FJ, Becker MD, Michels S. Optical coherence tomography angiography of the foveal avascular zone in retinal vein occlusion. Ophthalmologica. 2016;235(4):195-202.

4. Novais EA, Waheed NK. Optical coherence tomography angiography of retinal vein occlusion. In: Bandello F, Souied EH, Querques G, editors. Developments in ophthalmology. S. Karger AG; 2016. p. 132-8. Accessed 18 Aug 2018

5. Spaide RF, Klancnik JM Jr, Cooney MJ. Retinal vascular layers imaged by fluorescein angiography and optical coherence tomography angiography. JAMA Ophthalmol. 2015;133(1):45-50.

6. Kashani AH, Chen CL, Gahm JK, Zheng F, Richter GM, Rosenfeld PJ, Shi Y, Wang RK. Optical coherence tomography angiography: a comprehensive review of current methods and clinical applications. Prog Retin Eye Res. 2017:60:66-100.

7. Maran J, Srinivas S, Sadda SR. Evaluating ocular blood flow. Indian J Ophthalmol. 2017:65(5):337-46.

8. Carpineto P, Mastropasqua R, Marchini G, Toto L, Di Nicola M, Di Antonio L. Reproducibility and repeatability of foveal avascular zone measurements in healthy subjects by optical coherence tomography angiography. Br J Ophthalmol. 2016:100(5):671-6.

9. Dong J, Jia Y, Wu Q, Zhang S, Jia Y, Huang D, et al. Interchangeability and reliability of macular perfusion parameter measurements using optical coherence tomography angiography. Br J Ophthalmol. 2017:101(11):1542-9.

10. Linderman R, Salmon AE, Strampe M, Russillo M, Khan J, Carroll J. Assessing the accuracy of foveal avascular zone measurements using optical coherence tomography angiography: segmentation and scaling. Transl Vis Sci Technol. 2017;6(3):16.

11. Tsai G, Banaee T, Conti F, Singh R. Optical coherence tomography angiography in eyes with retinal vein occlusion. J Ophthalmic Vis Res. 2018;13(3):315 
12. Mihailovic N, Eter N, Alnawaiseh M. Foveale avaskuläre Zone und OCTAngiographie. Eine Übersicht aktueller Erkenntnisse [Foveal avascular zone and OCT angiography. An overview of current knowledge]. Ophthalmologe. 2019;116(7):610-6.

13. Tan CS, Lim LW, Chow VS, Chay IW, Tan S, Cheong KX, et al. Optical coherence tomography angiography evaluation of the parafoveal vasculature and its relationship with ocular factors. Investig Opthalmol Vis Sci. 2016;57(9):OCT224.

14. Nobre Cardoso J, Keane PA, Sim DA, Bradley P, Agrawal R, Addison PK, et al. Systematic evaluation of optical coherence tomography angiography in retinal vein occlusion. Am J Ophthalmol. 2016;163(93-107):e6.

15. Yu S, Lu J, Cao D, Liu R, Liu B, Li T, et al. The role of optical coherence tomography angiography in fundus vascular abnormalities. BMC Ophthalmol. 2016;16(1):1-7.

16. Casselholmde Salles M, Kvanta A, Amrén U, Epstein D. Optical coherence tomography angiography in central retinal vein occlusion: correlation between the foveal avascular zone and visual acuity. Investig Opthalmol Vis Sci. 2016;57(9):OCT242.

17. Samara WA, Shahlaee A, Sridhar J, Khan MA, Ho AC, Hsu J. Quantitative optical coherence tomography angiography features and visual function in eyes with branch retinal vein occlusion. Am J Ophthalmol. 2016;166:76-83.

18. Rispoli M, Savastano MC, Lumbroso B. Capillary network anomalies in branch retinal vein occlusion on optical coherence tomography angiography. Retina. 2015;35(11):2332-8.
19. Seknazi D, Coscas F, Sellam A, Rouimi F, Coscas G, Souied EH, et al. Optical coherence tomography angiography in retinal vein occlusion: correlations between macular vascular density, visual acuity, and peripheral nonperfusion area on fluorescein angiography. Retina. 2018;38(8):1562-70.

20. Enders C, Lang GE, Dreyhaupt J, Loidl M, Lang GK, Werner JU. Quantity and quality of image artifacts in optical coherence tomography angiography. PLoS ONE. 2019;14(1):e0210505.

21. Couturier A, Mané V, Bonnin S, Erginay A, Massin P, Gaudric A, et al. Capillary plexus anomalies in diabetic retinopathy on optical coherence tomography angiography. Retina. 2015;35(11):2384-91.

22. Sellam A, Glacet-Bernard A, Coscas F, Miere A, Coscas G, Souied EH. Qualitative and quantitative follow-up using optical coherence tomography angiography of retinal vein occlusion treated with anti-VEGF: optical coherence tomography angiography follow-up of retinal vein occlusion. Retina. 2017;37(6):1176-84.

\section{Publisher's Note}

Springer Nature remains neutral with regard to jurisdictional claims in published maps and institutional affiliations.
Ready to submit your research? Choose BMC and benefit from:

- fast, convenient online submission

- thorough peer review by experienced researchers in your field

- rapid publication on acceptance

- support for research data, including large and complex data types

- gold Open Access which fosters wider collaboration and increased citations

- maximum visibility for your research: over 100M website views per year

At BMC, research is always in progress.

Learn more biomedcentral.com/submissions 